\begin{tabular}{|c|c|c|}
\hline HLA-B27 positive & $7.7 \%$ & none \\
\hline
\end{tabular}

Conclusion PsoA patients with a delayed onset of the disease exhibit clinical symptoms that differ clearly from those of the other PsoA patients.

\section{SAT0043 ANKYLOSING SPONDYLITIS AND CARDIAC DISEASES}

${ }^{1} \mathrm{FM}$ Santos, ${ }^{2} \mathrm{~A}$ Alves, ${ }^{3} \mathrm{C}$ Catarino, ${ }^{3} \mathrm{~L}$ Bento, ${ }^{3} \mathrm{C}$ Cotrim, ${ }^{3} \mathrm{M}$ Carrageta, ${ }^{1} \mathrm{JC}$ Silva. ${ }^{1}$ Rheumatology; ${ }^{2}$ Internal Medicine; ${ }^{3}$ Cardiology, Garcia de Orta Hospital, Almada, Portugal

10.1136/annrheumdis-2001.395

Background Ankylosing Spondylitis (AS) and other spondyloarthropathies (SPA), are associated with certain cardiologic problems.

Objectives To identify coexisting AS and SPA in selected cardiac patients (pts) and to investigate the cardiac status of pts with an established diagnosis of AS.

Methods An observational study involving two pt. groups was undertaken: Group 1 were young and middle-aged patients ( $<50$ years at time of diagnosis), followed in the cardiology department for aortic valve disease and/or with a permanent pacemaker implanted. All pts were interviewed and examined. A pelvic X-ray and blood analysis for HLA B27 was performed. Group 2 were pts with an established diagnosis of AS and no clinical evidence of cardiovascular disease. A full history, clinical examination, 24-h Holter and doppler echocardiography were performed. Cardiac abnormalities were related to clinical features of AS.

Results Group 1: 14 pts with either an aortic valve replacement (AVR), aortic valve pathology and/or a permanent pacemaker were studied. 12 men and 2 women, with a mean age of 40 years (range 22-53) were observed. 9 pts had an AVR, 2 had aortic valva (AV) stenosis and 5 had a permanent pacemaker implamted. 2 of the pts had both an AVR and a permanent pacemaker. 1 of these pts was definitely diagnosed with AS and 2 pts were diagnosed as undifferentiated SPA. Group 2: 9 men and 8 women, with an average age of 43 years (min 23 and max 61) were included. Disease duration varied from 1 to 20 years with a mean of 8 . Four (24\%) pts had echocardiographic evidence of aortic valve thickening and regurgitation. Two pts also had left atrial dilatation. Holter exams were performed in 15 of the 17 pts. No significant conduction abnormalities or arrhythmias were apparent. The 4 pts with echocardiographic changes were older ( $>50$ years in 3 cases) or had a high Basmi index.

Conclusion Young pts with AV disease or conduction disorders should be screened for AS. Regular cardiac monitoring of AS pts may help prevent the long term cardiac complications associated with this condition.

\section{SAT0044 CLASS II MHC MOLECULES IN PATIENTS WITH SPORADIC ANKYLOSING SPONDYLITIS IN THE SOUTHERN EUROPEAN POPULATION}

VC Perez-Guijo, E Muñoz-Gomariz, A Escudero, M Romero, MA Aguirre, J Gonzalez, FG Martinez, MC Muñoz-Villanueva, C Castro, R Solana, J Peña, E Collantes. Rheumatology Service, Hospital Universitario Reina Sofia, Cordoba, Spain
Background To evaluate the relationship between the presence of HLA-DRB1 genes and predisposition to AS in a demographically well-defined population.

Objectives 113 individuals with sporadic (non-familial) Ankylosing Spondylitis (AS) from six different cities and 747 bone marrow donors (BMD) as control group.

Methods All individuals were typed for HLA-B27 by either flow cytometry with monoclonal antibodies or PCR-SSP, as well as for HLA-DRB using the Dynal ELITM SSO HLA-DRB Test (Dynal AS, Oslo, Norway). The Inno-Lipa DRB key and DRB Decoder (Innogenetics NV Zwijndrecht, Belgium), which is based on PCR-SSO technology, was used for high-resolution HLA -DRB typing.

Results Table 1 shows the results.

\begin{tabular}{|c|c|c|c|c|c|c|}
\hline & $\begin{array}{l}\text { B27(+) } \\
\text { AS (n } \\
=94)\end{array}$ & $\begin{array}{l}\text { B27(+) } \\
\text { BMD ( } \\
=56)\end{array}$ & $\begin{array}{l}\mathrm{p}^{*} \text { and } \mathrm{OR} \\
(95 \% \mathrm{Cl})\end{array}$ & $\begin{array}{l}\text { B27(-) } \\
\text { AS (n } \\
=19)\end{array}$ & $\begin{array}{l}\text { B27(-) } \\
\text { BMD (n = } \\
691)\end{array}$ & $\begin{array}{l}\mathrm{p}^{*} \text { and } \mathrm{OR} \\
(95 \% \mathrm{Cl})\end{array}$ \\
\hline DRB1 *01 & $\begin{array}{l}32 \\
(34 \%)\end{array}$ & $\begin{array}{l}31 \\
(55.3 \%)\end{array}$ & $\begin{array}{l}0.022 \text { and } 0.42 \\
(0.2-0.8)\end{array}$ & $8(42 \%)$ & $\begin{array}{l}140 \\
(20 \%)\end{array}$ & $\begin{array}{l}0.042 \text { and } 2.9 \\
(1-8)\end{array}$ \\
\hline DRB1 *04 & $\begin{array}{l}12 \\
(13 \%)\end{array}$ & $15(27 \%)$ & ns and 0.4 & $5(26 \%)$ & $\begin{array}{l}169 \\
(24 \%)\end{array}$ & ns and 1.1 \\
\hline DRB1 *06 & $\begin{array}{l}23 \\
(24 \%)\end{array}$ & $7(12 \%)$ & ns and 2.3 & $4(21 \%)$ & $\begin{array}{l}218 \\
(31 \%)\end{array}$ & ns and 0.58 \\
\hline DRB1 *09 & $3(3 \%)$ & $3(5 \%)$ & ns and 0.58 & $2(10 \%)$ & $15(2 \%)$ & ns and 5.3 \\
\hline
\end{tabular}

Conclusion The incidence of the DRB $1 * 01$ antigen in the studied population is significantly higher in B27(+) healthy individuals (BMD) than in $\mathrm{B} 27(+)$ AS patients. Also the incidence of this antigen is significantly higher in B27(-) AS patients than B27 (-) healthy individuals. This could implicate that in the absence of B27, the DRB1*01 antigen could take part in the development of the disease.

\section{SAT0045 SPONDYLODISCITIS IN ANKYLOSING SPONDYLITIS}

${ }^{1} \mathrm{P}$ Borman, ${ }^{1} \mathrm{U}$ Seckin, ${ }^{1} \mathrm{H}$ Gunduz, ${ }^{2} \mathrm{~N}$ Barca, ${ }^{2} \mathrm{~L}$ Damgaci. ${ }^{1}$ Department of Physical Medicine and Rehabilitation; ${ }^{2}$ Radiology, Numune Education and Research Hospital, Ankara, Turkey

\subsection{6/annrheumdis-2001.397}

Background Spondylodiscitis is a rare but well-known complication of ankylosing spondylitis (AS).

Objectives The aim of this study was to evaluate the incidence of spondylodiscitis and to determine the clinical and radiological appearance in a group of patients with AS.

Methods Thirty-two patients with a mean age of $36.4 \pm 11.4$ years were recruited to the study. Demographical, clinical and radiological characteristics of the patients were recorded. Bone scintigraphic evaluation and computerised tomography (CT) of the suspected lesions were determined.

Results Five (15.6\%) patients had radiographic abnormalities including irregular narrowed disc space borders and sclerosis of the adjent vertebral bodies in the thoracic and lumbar regions. All these patients had low back pain the clinical activity parameters were higher in $3(9.3 \%)$ of 5 patients. No fracture or pseudoarthrosis were observed. Technetium scan showed increased uptake in the vertebral disc space and vertebral end plates (L4- 